\title{
Formação, Inserção e Atuação Profissional na Perspectiva dos Egressos de um Curso de Psicologia
}

\author{
Training, Employability and Professional Performance Under the Perspective of Psychology \\ Bachelor Degree Holders \\ Formación, inserción y actuación profesional en la perspectiva de los egresados de \\ una carrera de Psicología
}

\section{Sueli Terezinha Bobato}

Psicóloga clínica. Doutoranda na Área de Oncologia. Mestre em Psicologia pela Universidade Federal de Santa Catarina (UFSC). Docente do Curso de Psicologia da Universidade do Vale do Itajaí, SC. E-mail: suelibobato@univali.br

\section{Claudia Meriane Stock}

Psicóloga formada pela Universidade do Vale do Itajaí, SC. E-mail: claudiamstock@gmail.com

Luciane Kaiser Pinotti

Psicóloga formada pela Universidade do Vale do Itajai, SC. E-mail: luciane.kaiserl@gmail.com

\section{Resumo}

Esta pesquisa teve como objetivo investigar a percepção de egressos de um curso de Psicologia sobre seu processo de formação, inserção e atuação profissional. Os dados foram coletados virtualmente por meio de um questionário semiestruturado, envolvendo 19 egressos. A análise foi realizada a partir da distribuição de frequência simples e da análise de conteúdo. Os resultados evidenciaram que o processo de inserção e atuação profissional se constitui como instância multifatorial, com variáveis relacionadas à formação, características pessoais e mercadológicas. Os participantes da pesquisa sugerem, como aspectos a serem aperfeiçoados, melhor articulação entre teoria e prática e ampliação dos contextos de estágio, diversificando a interlocução com outros campos do conhecimento. A maioria dos psicólogos realiza pós-graduação, e inseriu-se na vida profissional por meio de network. Os não inseridos atribuem esse fato à falta de especialização e de experiência, à baixa oferta de trabalho e remuneração. Evidencia-se a importância de contemplar no escopo das ênfases curriculares o desenvolvimento de habilidades comportamentais e planejamento de carreira para facilitar o processo de inserção profissional.

Palavras-chave: Transição acadêmico-profissional, formação em Psicologia, mercado de trabalho.

\section{Abstract}

This study aimed to investigate the perception of Psychology undergraduates on their training process, employability and professional performance. Data were collected virtually, through a semi-structured questionnaire involving 19 holders of a psychology bachelor degree. The analysis took place on simple frequency distribution and content analysis. The results showed that the process of employability and professional performance is multifactorial, with variables related to training, personal and market characteristics. As aspects to be improved, participants suggested a better articulation between theory and practice and enlargement of scope for training programs, expanding the interchange with other fields and practices. Most psychologists hold a graduation and entered professional market through networking. The interviewed who have not employed attribute it to factors as lack of expertise and experience, low job offer and remuneration. It highlights the importance of contemplating the development of behavioral skills and career planning in the scope of curricular emphases, to enable the professional integration process.

Keywords: Academic to professional transition, Psychology degree, labour market. 


\section{Resumen}

Este estudio objetiva investigar la percepción de los egresados de una carrera de Psicología sobre su proceso de formación, inserción y actuación profesional. Los datos se recogieron mediante un cuestionario virtual semiestructurado con 19 egresados. Se realizó el análisis a partir de la distribución de frecuencia simple y del análisis de contenido. Los resultados mostraron que el proceso de inserción y actuación profesional es multifactorial, con variables de instancia relacionadas con la formación, características personales y marketing. Los participantes de la investigación sugirieren, como aspectos a perfeccionar, mejor articulación entre teoría y práctica y ampliación de los contextos de prácticas, diversificando la interlocución con otros campos del conocimiento. La mayoría de los psicólogos realiza posgrado y se introdujo en la vida profesional a través de la red de contactos. Los psicólogos no introducidos en la vida profesional atribuyen el hecho a la falta de especialización y de experiencia, a la baja oferta de empleo y sueldo. Se evidencia la importancia de incluir en el ámbito de los énfasis curriculares el desarrollo de habilidades comportamentales y planificación de la carrera para facilitar el proceso de inserción profesional.

Palabras-clave: transición académica y profesional, formación en Psicología, mercado de trabajo.

A formação e atuação dos psicólogos no Brasil têm sido objeto frequente de estudos e discussões na última década, intensificando-se ainda mais com a comemoração dos cinquenta anos da regulamentação da profissão no Brasil em 2012. As discussões sobre a profissionalização dos psicólogos incidem sobre a identidade profissional, a função social da Psicologia e a interface junto às demais áreas do conhecimento, a necessidade de diversificação teórica e de flexibilização do currículo. Essas perspectivas constituem-se como desafios para o desenvolvimento das competências exigidas na formação profissional em Psicologia (Bardagi, 2008; Bastos \& Gondim, 2010; Rechtman, 2015; Yamamoto \& Costa, 2010).

As competências esperadas na formação do psicólogo são destacadas nas Diretrizes Curriculares Nacionais, instituídas pelo Conselho Nacional de Educação (Brasil, 2004; Brasil, 2011) a partir de uma formação voltada para a atuação profissional, para a pesquisa e para o ensino de Psicologia. As competências consistem na apropriação dos fundamentos epistemológicos, teórico-metodológicos e técnicos na investigação e atuação sobre os fenômenos e processos psicológicos em interface com campos afins do conhecimento, assegurando a compreensão integral e contextualizada do ser humano. Nesse sentido, o futuro psicólogo deve estar apto a desenvolver ações de prevenção, promoção, proteção e reabilitação da saúde psicológica e psicossocial por meio da tomada de decisões, comunicação, liderança no trabalho em equipe multiprofissional, gerenciamento dos processos de trabalho, além de apresentarem compromisso com a formação permanente. Bastos e Gondim (2010) complementam que a inovação nas práticas de atuação de modo consistente e responsável só é possível se profissional aprender a produzir o conhecimento.

Entre as estratégias essenciais para a qualidade da formação e respectiva qualificação da atuação profissional, destacam-se a melhoria da gestão universitária e a prestação de contas de seu desempenho para a sociedade (INEP, 2004). Dessa forma, frente às transformações sociais, passam a ter função fundamental estudos que aprofundem questões sobre as novas reconfigurações da ciência psicológica e as particularidades da atuação profissional do psicólogo, de modo a retroalimentar o processo formativo.

As pesquisas com os egressos no curso de Psicologia da universidade em que esta investigação foi realizada ocorrem desde 2003, e totalizam até o momento seis estudos, entre os quais, as pesquisas de Schaadt (2003), Antunes (2004), Peixer (2004), Camacho, (2007), Werlang (2009), Diniz e Pedri (2010). Os resultados destes estudos evidenciaram que uma das principais dificuldades apontadas pelos egressos estava relacionada à articulação entre teoria e prática no decorrer da graduação, pois os estágios ocorriam ao final do curso e não abrangiam todos os campos do conhecimento psicológico. Apontaram também 
a falta de experiência dos psicólogos recémformados, o que dificultava a inserção profissional. Neste sentido, novas pesquisas que investiguem a formação e atuação profissional são necessárias, avaliando a superação das fragilidades apontadas pelas pesquisas anteriores.

Considerando que os participantes desta pesquisa tiveram sua formação pautada pelas Diretrizes Curriculares de 2011, com estágios supervisionados distribuídos de forma sistemática e gradual ao longo do curso, a hipótese principal do respectivo estudo é que a articulação entre teoria e prática tenha sido alcançada no decorrer da graduação. Pressupõe-se que tal organização curricular favorece, desde os períodos iniciais do curso, a aproximação do formando com o exercício profissional, fornecendo elementos para a aquisição das competências, habilidades e conhecimentos básicos, considerando os níveis de complexidade relativos ao núcleo comum e formação específica.

Essa pesquisa também vem ao encontro do art. 16 das Diretrizes Curriculares Nacionais de 2011, que define que o projeto do curso deve prever procedimentos de autoavaliação periódica, dos quais deverão resultar informações necessárias para o seu aprimoramento. Considerando tais prerrogativas, esta pesquisa tem como objetivos identificar a satisfação dos egressos em relação à formação recebida, no que se refere às competências e habilidades demandadas à atuação profissional; levantar as estratégias de inserção profissional utilizadas pelos egressos e descrever os aspectos que facilitaram ou dificultaram o processo; obter informações sobre a atuação profissional dos egressos inseridos quanto a área, contextos e âmbitos de atuação; e levantar sugestões para superação das deficiências percebidas em sua formação e atuação profissional. Os resultados da pesquisa poderão permear importantes reflexões acerca de uma nova normatização para os cursos de graduação em Psicologia. Também poderão contribuir nos processos de alteração ou reorganizações necessárias, no que se refere à estrutura curricular e à dinâmica dos processos de aprendizagem, em prol do desenvolvimento das competências e habilidades requeridas, conforme estabelecido pelas Diretrizes Curriculares Nacionais.

\section{Método}

Para a realização deste estudo, foi utilizada a combinação metodológica entre a abordagem quantitativa e qualitativa. A amostra consistiu de 19 (21,35\%) dos 89 egressos do curso de graduação em Psicologia de uma universidade do sul do Brasil, formados a partir das Diretrizes Curriculares Nacionais para os cursos de graduação em Psicologia, estabelecida em 2011. Após a confirmação dos participantes quanto ao interesse em fazer parte do estudo, foi-lhes encaminhado o termo de consentimento livre e esclarecido, respeitando-se os seguintes critérios: realização de toda a graduação no respectivo curso e interesse em participar da pesquisa.

A coleta de dados foi efetuada a partir de um questionário semiestruturado adaptado de Camacho (2007), Werlang (2009), Diniz e Pedri (2010), e complementado por Bastos e Gondim
(2010), de forma a abranger as variáveis em estudo. O questionário, respondido por meio de correio eletrônico, foi composto por quatro partes: dados de identificação, dados sobre a graduação e pósgraduação, e inserção e atuação profissional. As três primeiras partes foram respondidas por todos os participantes. Aúltima, referente àinserção e atuação profissional, foi composta por cinco categorias, considerando as condições da realidade profissional em que se encontra o egresso após a conclusão do curso: condição A - egressos que não estão inseridos atualmente no mercado de trabalho no campo de atuação da Psicologia; condição B - egressos que estão parcialmente inseridos, exercendo atividade no campo da Psicologia e também em outra atividade remunerada fora do campo de atuação da Psicologia; condição C - egressos que estão inseridos apenas no 
campo de atuação da Psicologia; Condição D - egressos que nunca atuaram profissionalmente, dentro ou fora do campo de atuação da Psicologia; condição $\mathrm{E}$ - egressos que não exercem atividade profissional, dentro ou fora do campo da Psicologia atualmente, mas que já o fizeram no passado no campo da Psicologia.

As informações foram tabuladas eletronicamente por meio do programa Excel, a fim de permitir melhor visualização e compreensão dos dados. A análise da distribuição de frequência simples foi realizada com base no número de respostas obtidas, apresentada por meio de tabelas. A pesquisa foi aprovada pelo Comitê de Ética em Pesquisa da Universidade, respeitando-se os princípios da Resolução $n^{\circ}$ 466/12 do Conselho Nacional de Saúde, que dispõe sobre a realização de pesquisa em Psicologia com seres humanos. Os participantes receberam a devolução dos resultados da pesquisa por meio de correio eletrônico, após a apresentação do trabalho em banca avaliadora do estudo na respectiva universidade.

\section{Resultados e Discussão}

Os resultados apresentam inicialmente a caracterização da amostra, delineando o perfil dos egressos participantes. Em seguida, apresentam as dimensões relacionadas à formação recebida no curso de graduação, à continuidade da formação por meio de cursos de pós-graduação, e à inserção e atuação profissional. Esta última dimensão foi subdividida em cinco categorias, de acordo com a condição profissional atual do egresso.

\section{Caracterização da amostra}

Dos 19 egressos participantes, 14 são do sexo feminino. Com relação à faixa etária, dez dos egressos da pesquisa possuem idade até 25 anos, cinco egressos têm entre 26 a 30 anos e quatro possuem idade acima de 31 anos. O perfil dos egressos de Psicologia na amostra investigada está em consonância aos evidenciados nos resultados das pesquisas realizadas em âmbito nacional nas últimas décadas (Bastos \& Gondim, 2010; Pereira \& Pereira, 2003; Santos et al, 2014).

Em pesquisa realizada pelo IBOPE para o Conselho Federal de Psicologia em 2004, evidenciou-se um percentual de 91\% de psicólogas em uma amostra de 2.000 entrevistados (Bastos \& Gondim, 2010). Além disso, pesquisa mais recente realizada na Subsede Leste CRP-04, Santos et al. (2014) também evidenciou resultados semelhantes, corroborando com o que vem sendo afirmado em pesquisas anteriores: a tendência ao predomínio do gênero feminino na composição da categoria profissional.

\section{Formação recebida na graduação}

As Diretrizes Curriculares Nacionais para os cursos de graduação em Psicologia, elaboradas pelo Conselho Nacional de Educação (Brasil, 2004/2011), destacam a exigência de uma formação baseada na diversificação de métodos e estratégias, além de situações de aprendizagem que levem o estudante de Psicologia a demonstrar as competências norteadoras do currículo, como solução de problemas e geração de conhecimentos. Bastos e Gondin (2010), que endossam tal prerrogativa, enfatizam a necessidade de uma formação pluralista que assegure o contato do aluno com as principais orientações teóricometodológicas, e apresente as possibilidades de atuação no mercado de trabalho. Com base nesses pressupostos, esta pesquisa procurou identificar a percepção dos egressos em relação à formação recebida durante a graduação, conforme evidenciado na Tabela 1.

Dos 19 egressos, seis responderam que o curso proporcionou plenamente os conhecimentos teórico-metodológicos necessários para a atuação profissional e o conhecimento básico necessário às práticas profissionais. Já 13 egressos responderam que o curso proporcionou parcialmente tais conhecimentos, pois não conseguiu abranger todas as áreas de atuação nas disciplinas, nas abordagens, nos conteúdos e nos campos de estágio. No entanto, alguns reconhecem que é preciso haver aprofundamento dos conhecimentos 
Tabela 1

Respostas relacionadas à formação recebida na graduação

\begin{tabular}{lccc}
\hline & $\begin{array}{c}\text { Conhecimento teórico } \\
\text { metodológico }\end{array}$ & $\begin{array}{c}\text { Competências } \\
\text { necessárias }\end{array}$ & $\begin{array}{c}\text { Interface com outras } \\
\text { áreas/campos }\end{array}$ \\
\hline Plenamente & 06 & 06 & 05 \\
Parcialmente & 13 & 11 & 07 \\
Pouco & 00 & 02 & 05 \\
Não proporcionou & 00 & 00 & 01 \\
Não respondeu & 00 & 00 & 01 \\
\hline
\end{tabular}

por meio de cursos, especializações e congressos. Tais resultados podem ser analisados com base no que enfatizam Poppe e Batista (2012) ao descreverem que os cursos da área da saúde em geral vêm enfrentando algumas dificuldades, pois os alunos ainda estão na posição de receber o conhecimento diretamente dos professores. Os referidos autores argumentam que a atuação profissional se alterou, abrangendo distintos setores e contextos sociais, o que requer a generalização do conhecimento de modo a atender à diversidade das demandas de trabalho. Para tanto, os cursos devem nortear-se em referenciais que ampliem o perfil do futuro profissional, preparando-o para refletir sobre suas práticas e condutas mais adequadas baseadas em evidências científicas, o que requer o compromisso e a busca constante da educação por meio de atualizações.

Outro aspecto proposto pelas Diretrizes Curriculares Nacionais refere-se à interface com campos afins, com o objetivo de demarcar a especificidade do fenômeno psicológico e percebêlo em sua interação com fenômenos biológicos, humanos e sociais, assegurando uma compreensão integral e contextualizada dos fenômenos e processos psicológicos (Brasil, 2011). Com base nessa prerrogativa, evidenciou-se que, ao serem questionados se o curso de Psicologia propiciou interfaces com campos afins do conhecimento, promovendo a análise dos fenômenos/processos psicológicos em interação com outras áreas/ campos do conhecimento, cinco dos 19 egressos responderam plenamente que sim, justificando que o curso abrangeu muitas áreas e disciplinas afins, possibilitando uma visão geral sobre as interfaces da Psicologia com uma perspectiva integrada do ser humano. Já 12 egressos responderam que o curso propiciou parcialmente ou pouco as interfaces com campos afins do conhecimento, pois somente alguns professores e estágios proporcionaram o contato direto com outras áreas. Neste sentido, ficou a critério do interesse do aluno a busca deste conhecimento de acordo com suas possibilidades, por meio de atividades de extensão ou de estágios, articuladas a outras áreas/campos do conhecimento.

As Diretrizes Curriculares Nacionais propõem uma atuação generalista e flexível, de modo que a formação deve ser suficientemente abrangente para não se constituir como especialização, assegurando o respeito às singularidades institucionais, às vocações específicas e aos contextos regionais (Brasil, 2011). A esse respeito, Gondin (2002) defende que o desenvolvimento deve ser cultivado desde os tempos da graduação, baseado em uma formação mais ampla em possibilidades e experiências práticas, para que possam ser avaliadas possibilidades que atendam à exigência de um perfil multiprofissional. É necessário que, desde a vida acadêmica, sejam proporcionadas oportunidades para o desenvolvimento da maturidade pessoal e de uma identidade profissional, com o intuito de saber agir em diferentes contextos profissionais.

Nessa categoria, também foi questionado se o curso propiciou as competências, as habilidades e os conhecimentos necessários à avaliação, análise, prevenção e intervenção em processos psicológicos e psicossociais, e à promoção da qualidade de vida. Para os seis egressos que responderam que o curso atendeu plenamente a esse quesito, a formação recebida foi de boa 
qualidade: os professores eram capacitados, a matriz curricular apresentou abordagem teórica diversificada e voltada à promoção da qualidade de vida das pessoas, e os estímulos para o alcance das habilidades foram suficientes para o ingresso no mercado de trabalho. Os 13 egressos que responderam que o curso proporcionou pouco ou parcialmente essas competências ressaltam que os estímulos oferecidos pelo curso para o alcance das habilidades são suficientes para ingresso no mercado de trabalho. No entanto, reconhecem que as competências, as habilidades e os conhecimentos necessários também serão desenvolvidos posteriormente à graduação, com pós-graduações, estágios extracurriculares e futuras experiências profissionais. Evidenciouse uma ambiguidade nas respostas relacionadas às áreas de atuação, haja vista que dois egressos salientaram que, durante o curso, foi dada pouca ênfase às intervenções relacionadas à Psicologia Clínica e ao fazer do psicólogo no que se refere à saúde mental; dois participantes referem que as disciplinas destacaram muito a avaliação, a análise, a prevenção, mas as intervenções direcionaram-se principalmente à área clínica, deixando as áreas educacional, organizacional, jurídica e comunitária sem muitas alternativas de intervenção; e outros dois consideraram que a questão da prevenção foi abordada de forma superficial pelo curso.

Essas contradições na percepção da amostra investigada em relação à satisfação quanto ao desenvolvimento das competências que contribuíram para a inserção no mercado de trabalho podem ser explicadas pelo relato de outro participante para quem o desenvolvimento das competências depende do estágio que cada aluno fez. Salienta-se que, na transição entre as mudanças de matriz curricular, o estágio em Psicologia Clínica não foi obrigatório para a primeira turma formada pela matriz vigente. No entanto, os dados levantados podem ser úteis para uma reavaliação do curso no que se refere ao foco das intervenções, especialmente nas apontadas pelos egressos. Tal concepção demonstra que a maioria dos egressos evidenciou senso crítico a respeito de sua formação, e reconheceu a necessidade de fortalecer as competências, dando continuidade aos estudos para o alcançar a qualificação profissional.

Os resultados evidenciados vêm ao encontro com a afirmação de Borges (2006) e Bardagi (2008). Conforme concluem os autores, na área de Psicologia a graduação é insuficiente, sendo este o primeiro passo de uma longa caminhada em busca do aprimoramento profissional. Nesta etapa, as habilidades gerais necessárias começam a ser construídas, e algumas competências passam a ser valorizadas e aprimoradas; porém, precisam ser amplamente desenvolvidas com outras formações.

Com base nessas prerrogativas, a pesquisa avaliou a percepção dos egressos sobre as competências e habilidades desenvolvidas durante o curso e necessárias ao exercício adequado da profissão, atendendo ao que prevê as Diretrizes Curriculares Nacionais. Salienta-se que os itens "tomada de iniciativa" e "empreendedorismo", contidos na Tabela 2, estão relacionados à competência "Administração e Gerenciamento"; e o item "compromisso e responsabilidade com a formação" está relacionado à competência “educação permanente", conforme descrito nas Diretrizes Curriculares Nacionais (2004/2011). Estas modificações foram realizadas em prol da melhor compreensão dos participantes da pesquisa, tomando-se o cuidado para não alterar o conteúdo. Evidenciaram-se, de modo geral, resultados positivos variando entre satisfação plena e parcial, com exceção das competências relacionadas à tomada de decisão, liderança e empreendedorismo, em que houve dispersão nas respostas, principalmente na última competência, cujos resultados foram mais desfavoráveis.

Quanto às sugestões do que poderia ser melhorado em termos de competências e habilidades a serem desenvolvidas, prevalecem respostas relacionadas ao empreendedorismo (4), retratadas com justificativas como: "Saímos com pouca visão administrativa e o mercado de trabalho exige"; "O curso deveria nos preparar para sabermos como fazer uma proposta de trabalho, como cobrar os valores desta proposta".

Os egressos investigados relacionam ainda a oportunidade de estagiar em diversos contextos 
Tabela 2

Distribuição em frequência simples das respostas referentes às competências e habilidades desenvolvidas no curso de Psicologia.

\begin{tabular}{|c|c|c|c|c|c|}
\hline Competências desenvolvidas & Plenamente & Parcialmente & Pouco & $\begin{array}{c}\text { Não } \\
\text { atendeu }\end{array}$ & $\begin{array}{c}\text { Não } \\
\text { respondeu }\end{array}$ \\
\hline Atenção à saúde & 9 & 10 & & & \\
\hline Tomada de decisão & 4 & 9 & 6 & & \\
\hline Comunicação & 10 & 9 & & & \\
\hline Liderança & 2 & 10 & 7 & & \\
\hline Tomada de iniciativa & 4 & 11 & 2 & & 2 \\
\hline Empreendedorismo & 1 & 4 & 7 & 4 & 3 \\
\hline $\begin{array}{l}\text { Compromisso e responsabilidade } \\
\text { com a formação }\end{array}$ & 11 & 7 & & 1 & \\
\hline
\end{tabular}

de atuação profissional sob a orientação de professores in loco; essas experiências possibilitaram a observação de modelos de comportamento, posturas e práticas profissionais cuja percepção auxilia nas intervenções a serem realizadas após a graduação. Destacaram ainda que, além da tradicional avaliação teórica, foram realizadas avaliações comportamentais dos alunos relacionadas às competências e habilidades gerais durante a graduação, destacadas na tabela 2: tomada de decisão, comunicação, liderança, iniciativa, empreendedorismo, compromisso e responsabilidade com a formação.

No entanto, mencionaram serem necessárias, durante a graduação, articulação entre teoria e prática, atualização dos professores em relação à realidade do mercado profissional, firmeza e precisão em situações de indagações ou embate de ideias com outros profissionais ou cidadãos em geral. Para se aproximar de uma formação voltada para esses objetivos, sugerem ênfase à saúde como um todo, especialmente saúde mental e saúde do trabalhador; estímulo à tomada de decisão pelo aluno, instigando-o a questionamentos; maior tempo dedicado aos atendimentos clínicos e às discussões acerca desses. Os dados desta pesquisa são relevantes para a revisão da matriz curricular e principalmente a organização pedagógica dos professores, alertando para a necessidade de fortalecer as competências apontadas, principalmente as habilidades percebidas como de menor investimento no processo formativo do psicólogo.
A pesquisa verificou também se as atividades práticas realizadas nas disciplinas contribuíram para a compreensão dos conteúdos teóricos, bem como a articulação das disciplinas entre si e entre as disciplinas de formação do núcleo comum com as de formação específica. Conforme os resultados apresentados na Tabela 3 , sete egressos consideraram que as atividades práticas realizadas nas disciplinas contribuíram plenamente para a compreensão dos conteúdos teóricos, em contraposição a onze egressos que manifestaram que tal contribuição foi parcial. Na percepção dos participantes, foram poucas as atividades práticas, principalmente no período noturno, em que as oportunidades são escassas devido aos horários.

Em relação à articulação teórico-prática em cada uma das disciplinas e à articulação entre as disciplinas que compõem o núcleo comum da formação em Psicologia com as disciplinas que compõem a formação específica, nove participantes responderam que o curso proporcionou pleno equilíbrio neste aspecto, justificando que houve inter-relação entre as disciplinas, as quais se complementaram no decorrer do curso. Já para oito egressos o curso proporcionou equilíbrio parcial entre as disciplinas porque, apesar de haver relação entre as disciplinas, as articulações dependiam dos professores (3), muitas disciplinas deveriam ser obrigatórias em vez de eletivas, e deslocadas para outros períodos (2). Em relação aos dois egressos que justificaram que houve pouco equilíbrio, um relata que a teoria e a prática ainda estão distantes 
Tabela 3

Respostas relacionadas à articulação teórico-prática nas disciplinas e nas disciplinas entre si

\begin{tabular}{lcc}
\hline & $\begin{array}{c}\text { Articulação teórico-prática } \\
\text { nas disciplinas }\end{array}$ & $\begin{array}{c}\text { Articulação entre as disciplinas do } \\
\text { núcleo comum e formação específica }\end{array}$ \\
\hline Plenamente & 07 & 09 \\
Parcialmente & 11 & 08 \\
Pouco & 01 & 02 \\
Não proporcionou & 00 & 00 \\
\hline
\end{tabular}

uma da outra, e o outro esclarece que, nos estágios, muitos conteúdos foram novos, não foram vistos anteriormente ou foram trabalhados de forma superficial, ressaltando que este fator não resultou na "baixa" qualidade do curso.

Para Franco et al. (2007), a transformação da prática só ocorre a partir da compreensão dos pressupostos teóricos. A prática é intencional, precisa estar em constante processo de redirecionamento, com vistas a assumir uma responsabilidade social crítica, interlocutora e interpretativa das teorias implícitas, e mediadora de transformação para fins cada vez mais emancipatórios.

Para os egressos participantes, as disciplinas consideradas mais significativas para a formação foram a Psicologia Clínica (4), a Psicologia Social, Terapia Comportamental Cognitiva e Psicologia Organizacional e do Trabalho (3). Com uma menção foram relacionadas as disciplinas de Ambientação Profissional, Avaliação Psicológica, Psicopatologia, Fenomenologia, Sistêmica e Processos Grupais. E as disciplinas cursadas que menos embasaram para o exercício da profissão foram Psicomotricidade e Psicologia Organizacional e do Trabalho (3), seguidas de Psicologia Educacional e Comunitária (2).

Os resultados observados revelaram a presença de contradições entre os respondentes no que se refere à disciplina de Psicologia Organizacional e do Trabalho, que foi considerada por três participantes como uma das matérias mais significativas; porém, para três outros participantes foi a que menos embasou para o exercício da profissão. Salienta-se a importância de os egressos terem domínio das competências necessárias à uma formação sólida que contemple o amplo leque de possibilidades da Psicologia, as quais são alcançadas com o conhecimento teórico-metodológico viabilizado pelas diversas disciplinas que compõem a matriz curricular do curso.

Entre as disciplinas eletivas cursadas pelos participantes e sugeridas como obrigatórias, prevaleceram principalmente Gestalt Terapia (4) e Psicofarmacologia (3), Teoria Comportamental Cognitiva, Psicologia Jurídica (2), Psicologia da Sexualidade, Psicodrama, Fenomenologia, Gerontologia, Psicologia e Marketing, Psicologia Sistêmica e Avaliação Psicológica nas Organizações (1).

As Novas Diretrizes destacam ainda que o curso deve detalhar e explicitar pelo menos duas ênfases curriculares que assegurem a possibilidade de escolha por parte do aluno, devendo as instituições incorporar estágio supervisionado para garantir o desenvolvimento das competências específicas previstas (Brasil, 2004/2011). Os egressos foram questionados se os conteúdos e experiências contemplados nas ênfases propostas pelo curso foram suficientemente abrangentes e contribuíram para seu desenvolvimento profissional. Os resultados relacionados às duas ênfases oferecidas pelo curso na atual matriz curricular são apresentados na Tabela 4: "Saúde e Integralidade" e "Organizações e Comunidade".

Como evidenciado pelos dados relacionados na Tabela 4, a ênfase que mais contribuiu para o desenvolvimento profissional foi Saúde e Integralidade, com plena contribuição para 11 egressos, e contribuição parcial para oito egressos. As respostas demarcadas favoravelmente para esta ênfase são justificadas pelos aspectos identificação profissional com a área clínica, ótimos campos de atuação e professores excelentes, conforme 
Tabela 4

Frequência das respostas dos egressos sobre a abrangência e contribuição das ênfases propostas pelo curso para seu desenvolvimento profissional

\begin{tabular}{lcc}
\hline & Saúde e Integralidade & Organizações e Comunidade \\
\hline Plenamente & 11 & 07 \\
Parcialmente & 08 & 05 \\
Pouco & 00 & 03 \\
Não proporcionou & 00 & 01 \\
Não responderam & 00 & 03 \\
\hline
\end{tabular}

relatos a seguir: "Me sentia muito realizada pessoal e profissionalmente atendendo as pessoas... confesso que, particularmente, nunca me identifiquei com a área organizacional". As respostas demarcadas com contribuição parcial são justificadas pelo fato "dos orientandos não poderem escolher a abordagem teórica pela qual se identificam".

Salienta-se que três participantes relataram ter realizado apenas a ênfase Saúde e Integralidade no decorrer da graduação: "No último período optei pela clínica e não houve oportunidade de aprofundar a ênfase organizacional, o que faz falta hoje."; "(...) foram mais focadas para a área clínica.".

Os egressos que responderam que a ênfase em Organizações e Comunidade contribuiu pouco ou parcialmente para o seu desenvolvimento profissional referem justificativas variadas: limitação e qualidade de campo de atuação para os alunos que estudam em horário noturno; não identificação pessoal com a Psicologia Organizacional e do Trabalho, apesar de ser aquela que mais emprega; problemas de adaptação no campo de estágio; decepção com psicólogos supervisores de campo que não exercem o papel de psicólogo, mas de analista de Recursos Humanos; demora em relação à escolha do campo de estágio; mudança no campo por não haver possibilidade de intervenção; ações em pesquisa no respectivo estágio, não possibilitando experiência em empresa ou outra instituição.

Além disso, os egressos consideram que a abrangência da Psicologia, como área de conhecimento e campo de atuação profissional, não possibilita que o graduando tenha tempo suficiente para depreender todos os conhecimentos em sua complexidade durante a graduação. Nesse sentido, as Diretrizes Curriculares Nacionais enfatizam que o subconjunto de competências definido como escopo de cada ênfase deverá ser suficientemente abrangente para não configurar uma especialização em uma prática, procedimento ou local de atuação do psicólogo. E delimitam que devem ser oferecidas pelo menos duas ênfases para a formação dos graduandos da Psicologia.

Assim, foi solicitado aos participantes que escolhessem uma, ou mais de uma área de atuação da Psicologia, que mais poderia contribuir para o seu desenvolvimento profissional. Os resultados apontaram uma dispersão nas respostas, com maior frequência para Psicologia e Processos de Avaliação Diagnóstica (11), Psicologia e Processos de Gestão (9), Psicologia e Processos Educativos (8), Psicologia e Processos de Prevenção e Promoção de Saúde (7), e Psicologia e Processos de Investigação Científica (4).

Solicitou-se também que assinalassem os itens considerados importantes nos estágios obrigatórios para a sua formação profissional, podendo ser escolhida mais de uma opção. Constatou-se que houve um equilíbrio entre as respostas apresentadas, pois dos 19 egressos, 12 relacionaram: preparação para atuar em situações semelhantes; oportunidade de continuar a aprendizagem de maneira prática e reflexiva; desenvolvimento de autonomia, responsabilidade e poder de decisão em intervenções profissionais; possibilidade de iniciar a inserção no mercado de trabalho de modo a conciliar os conhecimentos teórico-práticos; e aprimoramento das habilidades para trabalhar em equipes multiprofissionais. E 11 dos 19 egressos assinalaram: aprimoramento da consciência ética profissional.

Os participantes consideram ser de fundamental importância a formação sólida do 
corpo docente, principalmente para assegurar a articulação teórico-prática nas disciplinas, bem como para relacionar os conhecimentos da sua disciplina com as demais disciplinas do currículo. Quando questionados se os professores do curso atenderam aos requisitos para alcançar a formação de qualidade, sete egressos justificaram que os professores têm formação excelente e domínio pleno do conteúdo, e ressaltaram que a formação de qualidade depende tanto do professor como do acadêmico. E 12 egressos responderam que, de modo geral, os professores do curso atenderam parcialmente aos requisitos para uma formação de qualidade. Alguns desses egressos apontam aspectos que podem rebaixar a qualidade de ensino como distanciamento de alguns professores com o mercado de trabalho, habilidades sociais dos professores e metodologia imprópria. Estes aspectos desfavorecem a articulação teóricoprática apontada anteriormente, bem como trazem implicações ao vínculo estabelecido com os alunos em determinadas disciplinas. Um dos participantes também ressalta a importância da coordenação do curso no processo de substituição de professores, com avaliação do domínio dos conhecimentos necessários à disciplina a ser ministrada.

\section{Formação específica}

Quando questionados sobre realização de cursos de pós-graduação, pôde-se constatar que 12 dos 19 participantes estão realizando ou já realizaram algum curso, enquanto apenas sete não deram continuidade à sua formação até a realização da presente pesquisa.

Conforme observado na Tabela 5, o curso mais frequentado pelos egressos é o de Especialização (9). Entre os principais fatores que motivaram o ingresso, referiram as necessidades do mercado de trabalho (8) e aprofundamento do conhecimento (6). Com relação à procura por formações específicas, Gondim (2002), em estudo com 53 estudantes de último ano de diversos cursos, constatou que a formação universitária é insuficiente para atender à demanda requerida no mercado de trabalho. Os participantes da respectiva pesquisa demonstraram reconhecer que, para se manter no mercado, é necessária permanente qualificação; contudo, o motivo principal que leva boa parte deles para a pósgraduação é o despreparo profissional.

O mercado de trabalho vem passando por transformações constantes, que dificultam muitas vezes a transição da graduação à inserção no mercado de trabalho. Assim como nas outras áreas, na Psicologia também há uma demanda crescente por parte do mercado de trabalho em buscar profissionais que vão além da técnica aprendida na graduação, mas que possuam certo desempenho em, por exemplo, informática e novas tecnologias, além de uma maior flexibilidade teórico-metodológica por parte dos profissionais. Em suma, segundo Bardagi e Bizzaro et al (2008), deixar de inserir-se apenas naquilo que diz respeito à sua profissão, mas também saber desenvolver-se com as diferentes áreas.

\section{Atuação profissional}

De acordo com Bastos e Gondim (2010), a atuação profissional é o conjunto de características que demarca o campo de trabalho do psicólogo. Esse conceito é usado para descrever os possíveis fazeres do psicólogo, conferindo identidade ao grupo de profissionais que se dedica às atividades exercidas na área. De acordo com Bastos e Gondim (2010), a atuação profissional é o conjunto de características que demarca o campo de trabalho do psicólogo. Esse conceito é usado para descrever os possíveis fazeres do psicólogo, conferindo identidade ao grupo de profissionais que se dedica às atividades exercidas na área. Atendendo a um dos objetivos desta pesquisa que consiste em obter informações sobre a atuação profissional, os dados foram subdivididos em cinco categorias, de acordo com a condição profissional dos egressos no momento da coleta de dados, evidenciadas na tabela 6, a seguir: ,

Evidencia-se que dos 19 egressos participantes dez estão inseridos no mercado de trabalho, seja no campo da Psicologia ou fora dela. Entre os 


\section{Tabela 5}

Distribuição das respostas em frequência simples referente aos cursos de pós-graduação realizados pelos egressos

\begin{tabular}{lcc}
\hline Cursos de Pós-Graduação & Variável & Frequência \\
\hline \multirow{2}{*}{ Participação do egresso } & Sim & 12 \\
& Não & 07 \\
Situação & Em andamento & 01 \\
& Paralisado & 01 \\
\hline \multirow{2}{*}{ Nível do curso } & Concluído & 09 \\
& Especialização & 02 \\
\hline \multirow{2}{*}{ Fatores que motivaram o ingresso } & Mestrado & 01 \\
\hline
\end{tabular}

\section{Tabela 6}

Distribuição em frequência simples das respostas referentes às condições profissionais dos egressos no momento da pesquisa

\begin{tabular}{lc}
\hline Condições profissionais dos egressos & Frequência \\
\hline Não estou inserido no mercado de trabalho no campo de atuação da Psicologia. & 6 \\
Estou inserido parcialmente, exerço atividade dentro do campo da Psicologia e & 4 \\
também em outra atividade remunerada fora do campo de atuação da Psicologia. & 6 \\
Estou inserido apenas no campo de atuação da Psicologia. & 1 \\
Nunca atuei profissionalmente dentro ou fora do campo da Psicologia. & 2 \\
Não exerço atividade profissional dentro ou fora do campo da Psicologia atualmente, & 19 \\
\hline mas já o fiz no passado no campo da Psicologia. & \\
\hline
\end{tabular}

motivos apontados como entraves da inserção no campo de atuação da Psicologia, destacam-se a falta de especialização (3), a falta de experiência, problemas pessoais, ausência de oferta de trabalho, proposta com baixa remuneração, pouca compreensão do papel do psicólogo e de sua atuação pela população não acadêmica (2) e a percepção de defasagem entre as habilidades e demandas do mercado (1).

Os resultados acima descritos também forma encontrados por Melo e Borges (2007) em pesquisa sobre a transição da universidade para o mercado de trabalho. Os autores evidenciaram que entre as principais dificuldades dos egressos de Psicologia para conseguir emprego estão a falta de experiência (33,3\%), falta de busca e objetivos (22,2\%), desatualização e desqualificação profissional (16,7\%). Além disso, os fatores mercado desfavorável e desproporção salárioremuneração $(5,6 \%)$ também foram levantados na pesquisa dos respectivos autores, assim como descrito pelos egressos desta pesquisa. Embora o estudo de Melo e Borges tenha sido realizado em 2007, já apontavam a necessidade de formação continuada dos profissionais que ingressam no mercado de trabalho. Esta prerrogativa é também estabelecida nas Diretrizes Curriculares Nacionais que apontam a necessidade de educação permanente dos profissionais, mantendo a responsabilidade e compromisso com a própria educação. Ressalta-se também a responsabilidade das instituições formadoras na garantia desse compromisso com as gerações futuras dos profissionais por meio da oferta de cursos de especialização, incluindo parcerias e cooperações técnicas com redes nacionais e internacionais (Brasil, 2011).

Os participantes foram questionados quanto ao desejo de inserir-se no mercado de trabalho. Dos seis que não se encontravam inseridos no campo 
da Psicologia, cinco demonstraram interesse em atuar na área, e um respondeu estar indiferente quanto à sua inserção no mercado de trabalho. As áreas de interesse apontadas foram: Psicologia Clínica, Saúde Pública, Psicologia Educacional, Psicologia Organizacional, Psicologia Social, além da pesquisa e docência. No que se refere às estratégias utilizadas para ingressar no campo da Psicologia, foram apontadas por cinco dos seis participantes, a entrega de currículos tanto em agências de emprego quanto nos departamentos de Recursos Humanos das empresas. Os contatos sociais, a realização de pós-graduação e de concursos públicos também foram levantados como possíveis estratégias para inserção no campo da Psicologia.

Os quatro egressos que se encontravam inseridos parcialmente citaram como outras atividades: secretária administrativa escolar, técnico de laboratório, supervisão de cursos de formação para o mercado de trabalho, e diretor de serviço em média complexidade (CAPS I). Dois destes participantes responderam que o curso de Psicologia contribuiu para o ingresso no seu trabalho e cargo atual, por meio do "Contato com profissionais que puderam orientar na prática profissional.".

Três desses quatro participantes disseram estar parcialmente satisfeitos com a função atual, considerando que a formação acadêmica contribuiu parcialmente para sua inserção: "Tive muita teoria, mas não tive oportunidade de realizar estágio na área que pudesse me fornecer conhecimento prático; e as disciplinas não nos possibilitaram ter uma noção da prática.".

Entre os motivos que os participantes atribuíram para estar atuando em outro campo além da Psicologia, foram citados o fato de já estarem exercendo essa atividade antes da formação (2), bem como o aspecto financeiro (2). Quanto à remuneração, evidenciou-se uma variação entre um a seis salários mínimos, o que justifica a satisfação parcial com a atividade desenvolvida dentro do campo da Psicologia, alegando ser um "Campo de difícil inserção, concorrido e mal remunerado.".
De acordo com Melo e Borges (2007), frente à dificuldade de inserção, os jovens recorrem a outras estratégias, como realização de um novo curso de graduação, empregos de menor remuneração para a aquisição de experiências, e muitas vezes, ocupação em cargos não compatíveis com sua formação. A dispersão e irregularidade na remuneração também são percebidas em uma pesquisa realizada por Malvezzi, Souza e Zanelli (2010), com aplicação de um questionário online com uma amostra de 834 participantes recémgraduados. Os respectivos autores evidenciaram que, enquanto $26,2 \%$ da amostra total dos psicólogos participantes ganha algo igual ou superior a 10 salários mínimos, 42,7\% ainda não atingem cinco salários mínimos.

Observou-se ainda que, para os egressos que não ingressaram no mercado de trabalho durante a graduação, a inserção aconteceu durante o primeiro ano após a graduação, mais especificamente nas áreas de Psicologia Organizacional e do Trabalho, Psicologia Clínica e Saúde Pública. Em relação à rápida inserção no mercado de trabalho, os quatro egressos inseridos tanto na Psicologia como em outras atividades levantaram como formas facilitadoras de inserção as seguintes estratégias: convite, recursos próprios, processo seletivo e network. Os locais de trabalho citados foram empresa privada, trabalho autônomo, consultório particular e serviço público. Descreveram ainda o desejo em atuar apenas no campo da Psicologia, sendo que para isso defendem alguns fatores facilitadores como exercer estágio não remunerado durante o curso (2), realização de cursos de especialização, segurança na formação recebida, amplo campo de atuação, network e histórico de trabalho (1). Entre os fatores que dificultam essa inserção relacionaram a baixa oferta de remuneração, distância entre teoria e prática, falta de experiência profissional, excesso de concorrentes no mercado e relativa baixa idade. Os resultados apontam para um paradoxo: enquanto a segurança na formação recebida é levantada como um facilitador para inserção no mercado de trabalho, a distância entre teoria e prática durante o curso de graduação é vista como um entrave para a inserção profissional. 
Dos seis egressos que estavam atuando apenas no campo da Psicologia, três afirmam que foi o seu primeiro emprego, e essa inserção ocorreu durante a graduação. Os demais (3) que se inseriram após a graduação tiveram uma inserção rápida, tendo ocorrido em até seis meses após a formatura. A atuação se deu nas áreas de Psicologia Organizacional e do Trabalho (2), Psicologia Clínica (2), Psicologia Escolar, Saúde Pública e Pesquisa; dois dos egressos atuam em duas áreas distintas.

Quanto ao local de trabalho dos respondentes que atuam somente na Psicologia, foram referidos os seguintes contextos: empresa privada, APAE, atividade autônoma, consultório particular, consultoria, órgão municipal e órgão federal. Além disso, a forma de admissão também foi variada, ocorrendo por meio de processo seletivo (3), voluntariado (2), convite, e cargo de confiança. Os seis participantes elencaram que o curso de Psicologia contribuiu para ocupar o cargo atual e para obter ascensão profissional, apesar de que apenas três afirmaram que o curso os auxiliou para aumentar seu padrão salarial. A faixa salarial variou de menos um salário mínimo a seis salários mínimos: de um a três salários mínimos (3), de quatro a seis salários (2), e menos de um salário mínimo (1).

No que se refere aos fatores que facilitaram a inserção no mercado de trabalho no campo da Psicologia, o network apareceu como predominante nas respostas (3), seguido de experiência profissional durante a graduação/estágio (2), competência/conhecimento (2), busca de conhecimentos além da graduação, complexidade dos fenômenos psicossociais, modernização, vontade e amor. Em uma pesquisa realizada por Melo e Borges (2007), também foi verificado que os fatores ambientais como a rede de contatos (network), independe de ser recém-graduado ou graduando, interfere diretamente facilitando o ingresso no mercado de trabalho, considerando a alta competitividade mercadológica.

Entre os fatores que dificultaram a inserção no mercado de trabalho no campo da Psicologia, os egressos desta pesquisa também apontaram a baixa remuneração e falta de experiência (2), além da falta de conhecimento para atuar junto a pessoas que apresentam algum tipo de deficiência, excesso de profissionais, pouco reconhecimento da profissão, ansiedade e pressa para atuar.

Dados similares foram evidenciados na pesquisa realizada por Melo e Borges (2007) com 20 jovens; destes, nove eram graduados e 11 recémgraduados, pertencentes a vários cursos, dentre eles o da Psicologia. Os resultados evidenciaram que a falta de experiência é um dos principais aspectos que dificultam a inserção profissional, com índice de 33,3\% nas respostas. Observou-se ainda que os jovens participantes deram ênfase à responsabilidade do próprio indivíduo para a não inserção ou dificuldade de inserir-se no mercado de trabalho. Segundo os autores, se os jovens aprendessem a se planejar profissionalmente, antecipando-se às tendências do mercado de trabalho, provavelmente reduziriam seus níveis de ansiedade e angústia frente às incertezas que o cercam.

Quando questionados sobre a relação entre suas atividades profissionais e formação acadêmica, três dos seis participantes disseram estar plenamente de acordo, uma vez que atuam no campo da Psicologia. Para um dos participantes, sua função está parcialmente de acordo com a formação recebida, e outros dois não responderam essa questão. Apesar disso, cinco dos participantes elencaram estar plenamente satisfeitos com sua profissão, mas não justificaram a resposta. O participante que estava pouco satisfeito justificou que os salários baixos não compensam o investimento feito na graduação e não é compatível com a responsabilidade que a profissão requer.

$E$, entre os dois respondentes que não exerciam atividade profissional no momento da pesquisa dentro ou fora do campo da Psicologia, mas já o fizeram no passado no campo da Psicologia, um deles atuou por um ano e meio com Psicologia Organizacional e do Trabalho, e o outro por oito meses com Psicologia Clínica. Segundo os egressos, os motivos por não estarem mais atuando profissionalmente estão relacionados 
a problemas pessoais, dedicação exclusiva à preparação para concurso público, bem como falta de perspectiva de crescimento profissional. E o egresso que nunca atuou dentro ou fora do campo da Psicologia justifica que a não inserção profissional decorreu de problemas pessoais, mas planeja inserção futura no mercado de trabalho.

Os dados apontam que a Psicologia Clínica e a Psicologia Organizacional e do Trabalho ainda estão entre os campos com maior facilidade de inserção, bem como de maior interesse por parte dos recém-graduados. Nesse sentido, é preciso ampliar o escopo da profissão para além da clínica, que acaba sendo a porta de entrada do recémformado no mercado de trabalho, oferecendo pluralidade teórica aliada à prática profissional.

\section{Considerações Finais}

Essa pesquisa teve por objetivos identificar o grau de satisfação de egressos de um curso de Psicologia sobre seu processo de formação; fazer um levantamento de informações sobre a inserção profissional, incluindo áreas, contextos e âmbitos de atuação profissional; verificar os aspectos que facilitaram e/ou dificultaram a inserção profissional dos egressos, bem como as estratégias utilizadas diante da não inserção. A partir da amostra investigada, evidenciou-se que o processo de inserção e atuação profissional inicial dos egressos de Psicologia constitui-se como instância multifatorial, com variáveis relacionadas à formação, às características pessoais do profissional egresso e características mercadológicas.

As discussões apresentadas revelam que, em geral, os egressos relataram satisfação parcial ou plena com a formação recebida e uma boa inserção no mercado de trabalho, haja vista que $31,6 \%$ dos entrevistados estão inseridos no campo da Psicologia, e $21 \%$ atuam no campo da Psicologia, juntamente com outra atividade fora deste campo. Salienta-se que os participantes da amostra investigada haviam finalizado sua graduação há no máximo um ano no momento da coleta de dados da pesquisa, encontrando-se ainda em processo de transição acadêmico-profissional.

A formação generalista foi um dos aspectos relacionados como positivos, pois possibilita aos egressos do curso de Psicologia o contato com diversas abordagens, contribui para a atuação destes profissionais em diversas áreas deste campo de conhecimento, potencializa experiências múltiplas, e pode representar a possibilidade de inserção bem-sucedida no mercado profissional. A partir dos resultados com a amostra investigada, evidenciou-se que a experiência nos estágios e nas demais práticas curriculares desenvolvidas nas ênfases propostas pelo curso não foram avaliadas com satisfação plena no que se refere à integração entre teoria e prática, reafirmando a necessidade de aprofundar o debate em relação a esse tema. Tais evidências ressaltam a importância de contemplar no escopo das ênfases propostas pelo curso o desenvolvimento de habilidades comportamentais para além das competências técnicas, haja vista que os egressos participantes desta pesquisa ressaltaram essa questão como sugestão para promover melhoria do curso de Psicologia. Sugere-se, portanto, o fomento de estratégias formativas que favoreçam as habilidades de empreendedorismo e tomada de decisão na profissão e carreira profissional. Uma proposta, com base nos resultados apresentados nesta amostra, é que a disciplina de empreendedorismo se constitua como uma disciplina obrigatória na matriz curricular do Curso.

Tais evidências ressaltam a necessidade do planejamento da carreira já iniciado no período de graduação para facilitar o processo de inserção profissional, buscando estratégias que aperfeiçoem o desenvolvimento das competências teóricometodológicas e comportamentais, e favoreçam a inserção e atuação profissional de qualidade.

Salientam-se as limitações importantes desta pesquisa. O número de participantes foi restrito para representar a realidade dos egressos do curso; 
além disso, esses egressos encontravam-se em início de carreira profissional, o que também pode ter influenciado no nível de remuneração abaixo do valor de pesquisas de âmbito nacional. Sugere-se, portanto, a realização de outros estudos com egressos envolvendo uma amostra maior, bem como a realização de estudos com egressos formados há mais tempo e com maior experiência no mercado de trabalho. Conclui-se, no entanto, que as percepções sobre a formação recebida e o levantamento sobre as trajetórias de carreira dos egressos aqui contemplados podem fornecer informações relevantes, tanto para discutir mudanças curriculares, quanto para conhecer a realidade profissional.

\section{Referências}

Antunes, T. H. (2004). A inserção no mercado de trabalho dos egressos do curso de Psicologia - UNIVALI Campus - 1 2002/II - 2004/I. Monografia (Graduação em Psicologia). Universidade do Vale do Itajaí, Itajaí.

Bastos, A. V. B., \& Gondim, S. M. G. (2010). O Trabalho do Psicólogo no Brasil. Porto Alegre: Ed. Artmed.

Bardagi, M. P.; Bizarro, L., Andrade, A. M. J.; Audibert, A. \& Lassance, M. C. P. (2008). Avaliação da formação e trajetória profissional na perspectiva de egressos de um curso de psicologia. Psicologia: Ciência e Profissão, 28(2), 304-315. doi: 10.1590/S1414-98932008000200007

Bardagi, M. P., Lassance, M. C. P. \& Paradiso, A. C. (2003). Trajetória Acadêmica e Satisfação com a Escolha Profissional de Universitários em Meio de Curso. Revista brasileira de orientação profissional, 4(1-2), 153-166.

Borges, M. C. (2006). A construção de um psicoterapeuta: formação e habilidades. Trabalho de Conclusão de Curso - Monografia II. RJ. Recuperado de http://newpsi.bvspsi.org.br/tcc/104.pdf

Brasil. Ministério da Educação (2004). Diretrizes Curriculares Nacionais para os Cursos de Graduação em Psicologia. Resolução nº 8, de 7 de maio de 2004. Diário Oficial da União. Brasília. Brasil. Ministério da Educação (2011). Diretrizes Curriculares Nacionais para os Cursos de Graduação em Psicologia. Resolução no 15 de 15 de março de 2011. Diário Oficial da União. Brasília.

Camacho, G. K. (2007). Relatório final de Estágio Supervisionado em Psicologia Organizacional e do Trabalho. Itajaí: UNIVALI.

Diniz, H. M. V., \& Pedri, K. R. (2010). Transição entre a formação, inserção e atuação profissional dos egressos de um Curso de Psicologia do Vale do Itajaí. Itajaí: UNIVALI.

Franco, M. A. S., Libaneo, J. C., \& Pimenta, S. G. (2007). Elementos para a formulação de diretrizes curriculares para cursos de pedagogia. Cadernos de Pesquisa, 37(130), 63-97. doi: 10.1590/S0100-15742007000100005

Gondim, S. M. G. (2002). Perfil profissional e mercado de trabalho: Relação com a formação acadêmica pela perspectiva de estudantes universitários. Estudos de Psicologia, Natal, 7(2), 299-309. doi: 10.1590/S1413294X2002000200011
Instituto Nacional de Estudos e Pesquisas Educacionais Anísio Teixeira (INEP) (2004). SINAES - Sistema Nacional de Avaliação da Educação Superior: bases para uma nova proposta de avaliação da educação superior brasileira. $2^{a}$. ed. Brasília: INEP.

Malvezzi, S., Souza, J. A. J. \& Zanelli, J. C. (2010). Inserção no mercado de trabalho os psicólogos recém-formados. In A. V. B., Bastos \& S. M. G., Gondim (pp. 85-106). O trabalho do psicólogo no Brasil. São Paulo: Artmed.

Melo, S. L., \& Borges, L. O. (2007). A Transição da Universidade ao Mercado de trabalho na Ótica Jovem. Psicologia: Ciência e Profissão, 27(3), 376-395.

Pereira, F. M. \& Pereira, A. N. (2003). O Psicólogo no Brasil: Notas sobre seu processo de profissionalização. Psicologia em Estudo, 8(2), 19-27. doi: 10.1590/S141373722003000200003

Peixer, J. R. (2004). Formação e Inserção no Mercado de Trabalho: A percepção dos egressos do currículo IV do curso de Psicologia da UNIVALI. Monografia (Graduação em Psicologia). Universidade do Vale do Itajaí, Itajaí.

Poppe, A. R. S., \& Batista, S. H. S. S. (2012). Formação em Psicologia no contexto das Diretrizes Curriculares Nacionais: Uma discussão sobre os cenários da prática em saúde. Psicologia: Ciência e Profissão, 32(4), 986-999 doi: 10.1590/S1414-98932012000400016

Rechtman, R. (2015). O futuro da psicologia brasileira: uma questão de projeto político. Diversidade e Saúde, Salvador, 4(1), 69-77.

Santos, K. R., Monteiro, L. G., Torres, M. L. C., Sousa, L. G., \& Coelho, A. R. (2014). Perfil dos Psicólogos inscritos na Subsede Leste do CRP-04. Psicologia: Ciência e Profissão, 34(4), 864-878. doi: 10.1590/1982-370000162013

Schaadt, A. (2003). Egressos do curso de Psicologia da UNIVALI: Percepção sobre sua Formação e Inserção no Mercado de Trabalho. Monografia (Graduação em Psicologia). Itajaí: UNIVALI.

Teixeira, M. A. P., \& Gomes, W. B. (2004). Estou me Formando... E Agora? Reflexões e Perspectivas de Jovens Formandos Universitários. Revista Brasileira de Orientação Profissional, 5(1), 47-62. 
Werlang, C. L. (2009). Formação e inserção profissional dos egressos do Curso de Psicologia da UNIVALI/Campus Itajaí2007/I a 2008/II. Monografia (Graduação em Psicologia). Itajaí: UNIVALI.
Yamamoto, O. H. \& Costa, A. L. F. (2010). Escritos sobre a profissão de psicólogo no Brasil. Natal: EDUFRN. Recuperado de http://newpsi.bvs-psi.org.br/ ebooks2010/pt/Acervo_files/Escritos-prof-psicologono_Brasil.pdf 